\title{
Plasma-catalytic Efficiency on the Discolouration of Sunset Yellow FCF in a Glidarc Plasma Reactor in Presence of $\mathrm{WO}_{3}$ Used as Catalyst
}

\author{
Gervais B. Y. Ndiffo, Serge A. Djepang, Romaric L. Seutcha, and Samuel Laminsi
}

\section{ABSTRACT}

In this work, we highlight the plasma-catalytic effect of gliding arc discharge on the bleaching of azo dye sunset yellow FCF in aqueous solution. The effect has been studied in the presence of tungsten oxide as a catalyst in the glidarc reactor. The catalyst has been synthesized via acid precipitation process. The product obtained was characterized by X-ray powder diffraction (XRD), Fourier Transform Infrared (FTIR) and Nitrogen Physisorption. The results showed firstly monoclinic structure of $\mathrm{WO}_{3}$ catalyst. The maximum bleaching rates obtained are $17 \%$ and $52.5 \%$ after $30 \mathrm{~min}$ for initial dye concentration of $25 \mathrm{mg} . \mathrm{L}^{-1}$ for plasma alone and plasma-catalyst, respectively. These results have clearly shown that gliding arc discharge has a double effect, in on hand as a source of hydroxyl radical and on other hands as a source of radiation able to excite the catalyst. The effects of initial $\mathrm{pH}$ and photocatalyst loading have been studied.

Keywords: Discouloration, gliding arc discharge, plasma-catalytic, $\mathrm{WO}_{3}$.

\section{INTRODUCTION}

Dyes are responsible for about one-tenth of environmental pollutants. Dyes from most agro-food industries, textures, pharmaceuticals, etc., which are directly diverted into the environment without prior treatment [1]. Different methods are used for the treatment of waters containing dyes, including photocatalysis [2], which has received an interest in recent years due to the possibility of destroying the organics pollutants in water or air. Among the different types of photocatalysts, tungsten oxide $\left(\mathrm{WO}_{3}\right)$ has shown interesting properties. The tungsten oxide (VI) is a n-type semiconductor oxide with a band-gap energy approximately 2.5-2.8 eV [3], [4]. The different properties of tungsten oxide (VI) have recently generated significant interests for a wide variety of applications in dye-sensitized solar cells, water splitting photocatalyst as main catalyst, photocatalysis, microelectronics, colloidal quantum dot LEDs, detecting of hazardous pollutants such as NOx and other alcohol gases, surface acoustic wave gas sensor, photochromic, electrochromic [5]-[11] To synthesize $\mathrm{WO}_{3}$ different approaches have been used, thermal decomposition, ionexchange methods, pyrolysis, sol-gel, colloidal processes, Glidarc- $\mathrm{WO}_{3}$ system.
Published Online: February 4, 2021

ISSN: $2684-4478$

DOI : $10.24018 /$ ejchem.2021.2.1.45

G. B. Y. Ndiffo*

Faculty of Mathematics, Physics and Informatics, Comenius University, Slovakia.

Inorganic Chemistry Department, University of Yaounde, Cameroon.

(e-mail: zarby.yemeli@yahoo.fr)

S. A. Djepang

Institute of Technology, University of Ngaoundere, Cameroon.

Inorganic Chemistry Department, University of Yaounde, Cameroon.

(e-mail: sdjepang ${ }^{\circledR}$ yahoo.fr)

R. L. Seutcha Author

Inorganic Chemistry Department, University of Yaounde, Cameroon.

(e-mail: roland_seutcha@yahoo.fr) S. Laminsi

Inorganic Chemistry Department, University of Yaounde, Cameroon.

(e-mail: laminsi@yahoo.fr)

*Corresponding Author

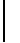

precipitation [6], [10], [12]-[18], among other methods. During the last 10 years, $\mathrm{WO}_{3}$ has attracted significant scientific interest, the number of research articles related to $\mathrm{WO}_{3}$ increased. This rising shows that $\mathrm{WO}_{3}$ is becoming a more and more important in the field of photocatalytic application. Laroussi et al. and Brisset at al. showed that the gliding arc plasma (GAP) is able to generate the ultraviolet radiation [19], [20], which can activate the catalyst surface and thus generate active dissociated electron hole pairs. The coupling of GAP with photocatalysis has been largely studied to improve organics dyes removal [21]-[25].

The goal to reach in this study is to investigate the efficiency of gliding arc plasma (GAP) to enhance the bleaching rate of Sunset Yellow FCF (SY-FCF) in presence of acid assisted synthesis monoclinic tungsten oxide in the glidarc reactor. The bleaching skill of the dye solution treated by Glidarc was compared to that of the solution treated by the 


\section{MATERIAL AND METHOD}

\section{A. Material}

Sunset yellow FCF ((SY-FCF), $\left.\left(\mathrm{C}_{16} \mathrm{H}_{10} \mathrm{~N}_{2} \mathrm{Na}_{2} \mathrm{O}_{7} \mathrm{~S}_{2}\right)\right)$ oracid-6-hydroxy-5-[(4-sulfophenyl)azo]-2-naphthalenesulfonic disodium salt, molar mass: $452.37 \mathrm{~g}$ was purchased from Sigma-Aldrich and was used as target dye with absorption maxima at $482 \mathrm{~nm}$. SY-FCF stock solution (500 $\mathrm{mg} / \mathrm{L}$ ) was prepared in distilled water and kept in a dark condition before experiments. SY-FCF chemical structure is shown in Fig. 1, sodium tungstate dihydrate $\left(\mathrm{Na}_{2} \mathrm{WO}_{4} \cdot 2 \mathrm{H}_{2} \mathrm{O}\right.$, 99\%) was purchased from Merck-Darmstadt, sulfuric acid 98 \%obtained from Riedel-de Haën Germany, and distilled water was used throughout the sample's preparation.

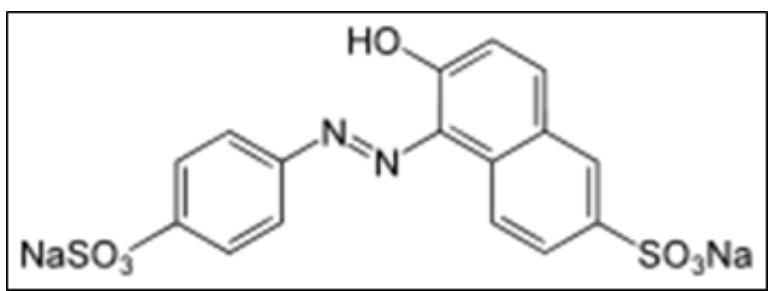

Fig. 1. Structure of sunset yellow FCF (SY-FCF).

\section{B. Apparatus}

The experimental apparatus used for this study is represented in (Fig. 2); it has been described by several author [22], [24], [25]. The formed species in glidarc plasma reactor such as $\mathrm{OH}^{\bullet}$ radicals $\mathrm{H}_{2} \mathrm{O}_{2}$ play an important role for the strong oxidizing effects [26]. Equation 1 to 11 represent the formation of reactive oxygen and nitrogen species in liquid through liquid/gas interface and develop in the liquid target.

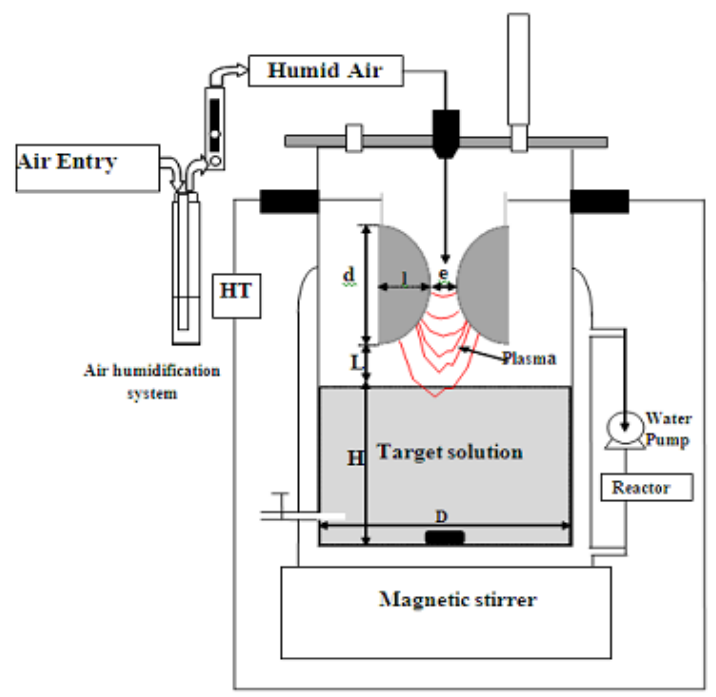

Fig. 2. Experimental setup of gliding arc discharge.

$$
\begin{aligned}
& \mathrm{H}_{2} \mathrm{O}+\mathrm{e}^{-} \rightarrow \mathrm{H}^{\bullet}+\mathrm{OH}^{\bullet}+\mathrm{e}^{-} \\
& \mathrm{O}_{2}+\mathrm{e}^{-} \rightarrow{ }^{\bullet} \mathrm{O}+{ }^{\bullet} \mathrm{O}+\mathrm{e}^{-} \\
& \mathrm{N}_{2}+\mathrm{e}^{-} \rightarrow{ }^{\bullet} \mathrm{N}+\bullet \\
& \bullet \\
& { }^{\bullet}+\mathrm{O}_{2} \rightarrow \mathrm{NO}^{\bullet}+\mathrm{e}^{-} \mathrm{O} \\
& \mathrm{H}^{\bullet}+\mathrm{O}_{2} \rightarrow \mathrm{HO}_{2}^{\bullet}
\end{aligned}
$$

$$
\begin{aligned}
& \mathrm{HO}_{2}^{\bullet}+\mathrm{NO}^{\bullet} \rightarrow \mathrm{NO}_{2}+\mathrm{HO}^{\bullet} \\
& \mathrm{NO}_{2}^{\bullet}+\mathrm{HO}^{\bullet} \rightarrow \mathrm{H}^{+}+\mathrm{NO}_{3}^{-} \\
& \mathrm{NO}{ }^{\bullet} \mathrm{HO} \bullet \rightarrow \mathrm{HNO}_{2} \\
& \mathrm{HNO}_{2} \rightarrow \mathrm{H}^{+}+\mathrm{NO}_{2}^{-} \\
& \mathrm{NO}{ }^{\bullet}+\bullet \\
& \mathrm{O}_{2}+{ }^{\bullet} \mathrm{O} \rightarrow \mathrm{NO}_{2}
\end{aligned}
$$

\section{Synthesis of photo-catalyst}

$10 \mathrm{~g}$ of $\mathrm{Na}_{2} \mathrm{WO}_{4} .2 \mathrm{H}_{2} \mathrm{O}, 98 \%$ purity were added in $500 \mathrm{~mL}$ distilled water followed by stirring to obtain the aqueous transparent solution. The concentrated Sulfuric acid (32\%) was dropped slowly into the solution until a yellowish tungstic solution was thoroughly formed. The precipitate was allowed to settle for 3 hours; afterward, the sediment was settled down for natural dryness. Then the formed yellowish precipitate was washed several, after that the product was dried in the oven $\left(100^{\circ} \mathrm{C}\right)$. Finally, the material obtained was calcined at $800{ }^{\circ} \mathrm{C}$ for $3 \mathrm{~h}$ in a tube furnace to obtain the yellowish coloured $\mathrm{WO}_{3}$.

The pictures a, b, c, and d show by figure 3 represent the different steps of $\mathrm{WO}_{3}$ synthesis. Initially the salt solution of $\mathrm{NaWO}_{4} .2 \mathrm{H}_{2} \mathrm{O}$ is colourless, then we added sulfuric acid $4 \mathrm{M}$ with $30 \mathrm{~s}$ rapid stirring, the colour of solution turns to yellowish. After 3 hours of aging, we obtained yellow precipitate hydrated of tungsten oxide $\left(\mathrm{WO}_{3} \cdot \mathrm{nH}_{2} \mathrm{O}\right)$. Finally, the yellowish powder of tungsten oxide is obtained by calcination of $\mathrm{WO}_{3} \cdot \mathrm{nH}_{2} \mathrm{O}$ at $800{ }^{\circ} \mathrm{C}$.

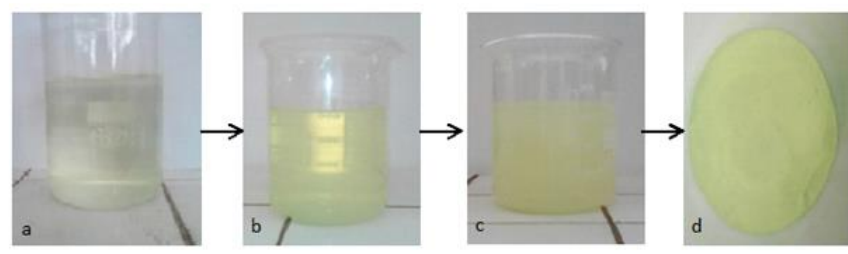

Fig. 3. Pictures of different steps of $\mathrm{WO}_{3}$ synthesis:

a) aqueous solution of $\mathrm{NaWO}_{4} \cdot 2 \mathrm{H}_{2} \mathrm{O}$, b) a + Sulfuric Acid stirring $30 \mathrm{~s}$ c) a + Sulfuric Acid $3 \mathrm{~h}$, d) $\mathrm{WO}_{3}$ after calcination at $800{ }^{\circ} \mathrm{C}$.

\section{Characterization}

The X-ray powder diffraction (XRD), Fourier Transform Infrared (FTIR), and Nitrogen Physisorption were performed as described in the following article [23], [24].

\section{E. Experimental Procedure and Analytical Methods}

An exact volume of $420 \mathrm{~mL}$ of dye solution of Sunset Yellow FCF $\left(25 \mathrm{mg} . \mathrm{L}^{-1}\right)$ were filled in the gliding arc plasma reactor and the air flow rate was set at $13.33 \mathrm{~L}_{\mathrm{min}}{ }^{-1}$. The treatments of the liquid dye are evaluated in function of the treatment time $t^{*}(\min )$ by keeping fix. The treatment times were respectively: 5,10,15, and $30 \mathrm{~min}$. The solutions were exposed to the discharge without and with $\mathrm{WO}_{3}$ added (at 0.5 , $1,1.5,2$, and 2.5 g. $\mathrm{L}^{-1}$ concentration) with the aim of optimizing the quantity of catalyst, before analysis, the aqueous samples were centrifuged to remove $\mathrm{WO}_{3}$ agglomerates. UV-vis analyses were performed on a UV-vis spectrophotometer (AQUALITIC) to follow the fading process for each treatment type. The residual absorbance of 
Sunset Yellow FCF after each exposure time was determined by spectrophotometry at $\lambda_{\max }=482 \mathrm{~nm}$. The decreased dye absorbance was measured and bleaching efficiency (BE) was calculated using the equation:

$B E=\frac{(\mathrm{Ao}-\mathrm{Ai})}{\mathrm{Ao}} \times 100$

where $A_{o}$ represents the input absorbance of the dye solution and $\mathrm{Ai}$ represents the output absorbance (after the reaction).

\section{RESULTS AND DISCUSSION}

\section{A. Structural characterization}

The XRD of the synthesized $\mathrm{WO}_{3}$ powders at the temperature of $800{ }^{\circ} \mathrm{C}$ is depicted in Fig.4, the main peaks at $2 \theta=23.1^{\circ}, 23.7^{\circ}$, and $24.4^{\circ}$ are assigned to Miller indices (002),(020), and (200), respectively and all diffraction lines were correctly assigned to the monoclinic polymorph of $\mathrm{WO}_{3}$ $\left(\mathrm{m}-\mathrm{WO}_{3}\right)$ according to the JCPDS Card No. 01-083-0950. The average crystallite size (D) of the $\mathrm{WO}_{3}$ sample was evaluated by using the below formula [27]:

$$
D=\frac{0.90 \lambda}{\beta \cos \theta}
$$

where $\lambda(0.1548 \mathrm{~nm}, \mathrm{CuK} \alpha)$ is the $\mathrm{X}$-Ray wavelength, $\beta$ is the breadth of the diffraction lines in radian and $\theta$ is the diffraction angle in degree. The reflecting peak at the crystal plane of (200) for the sample is chosen to estimate the average size of the $\mathrm{WO}_{3}$, the crystallite size estimated is about 35.05 nm.

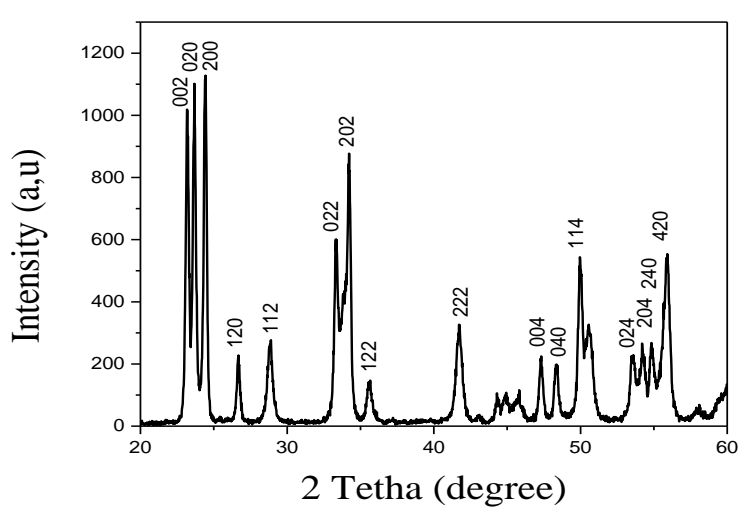

Fig. 4. XRD patterns of $\mathrm{WO}_{3}$ sample synthesized.

\section{B. FTIR Spectroscopy}

To confirm the monoclinic tungsten oxide, the powder was characterized by FTIR method. This analysis is a good way to provide the absorption peaks which agree the frequencies of vibrations of the sample. Fig. 5 shows the FTIR spectra of the synthetized tungsten oxide calcined at $800{ }^{\circ} \mathrm{C}$ (wavelength range $400-4000 \mathrm{~cm}^{-1}$ ). The tungsten oxide vibrations are found in the infrared region of $1200-600 \mathrm{~cm}^{-1}$, which correspond to $\mathrm{W}-\mathrm{O}$ stretching [28], [29],bending and lattice mode [30]. The peak $1624 \mathrm{~cm}^{-1}$ may be attributed to $\mathrm{W}-\mathrm{OH}$ vibration. The figure also shows a strong band at $815 \mathrm{~cm}^{-1}$ for $\mathrm{W}-\mathrm{O}-\mathrm{W}$ bridging mode also the presence of a broad W-O-W bridging stretching band centred at $658 \mathrm{~cm}^{-1}$ is noticed [30]. The peak at $815 \mathrm{~cm}^{-1}$ is attributed to the $\mathrm{O}-$
$\mathrm{W}-\mathrm{O}$ stretching vibration mode of the bridging oxygen atoms [29], [31]. The absorption band in the range of $3429 \mathrm{~cm}^{-1}$ can be due to the symmetric stretching vibrations and intercalated water molecules $\left(\mathrm{WOH} . . . \mathrm{H}_{2} \mathrm{O}\right)$.

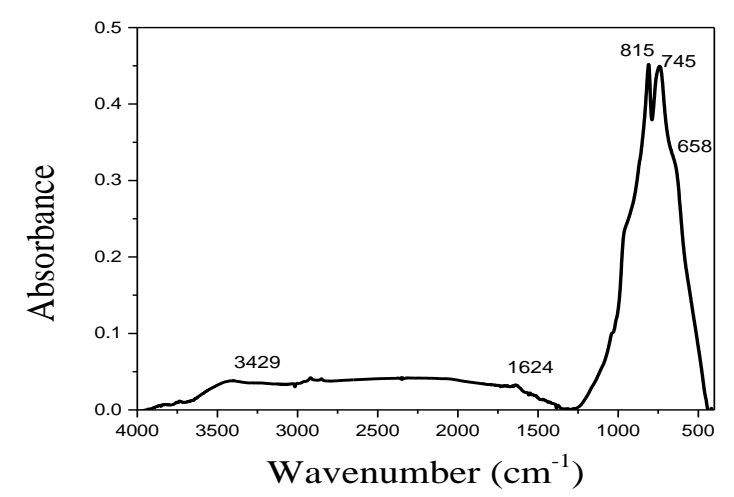

Fig. 5. FTIR spectra of tungsten oxide.

\section{Nitrogen Physisorption Analysis}

The nitrogen adsorption/desorption isotherms and the BJH pores distribution curve of prepared tungsten oxide were explored by nitrogen physisorption analysis (Fig. 6). The results exhibited an isotherm with a hysteresis loop, typical of type IV isotherm and illustrating the presence of mesopores, moreover, the hysteresis loop is more shifted to high relative pressure (0.9-1), suggesting the presence of macropores $(>50 \mathrm{~nm})$ [21], [23] (Fig. 6a). The pore distribution (Fig. 6b) shows a single band, typical of monomodal distribution and illustrating the homogeneity of spores sizes. The specific surface area $\left(\mathrm{S}_{\mathrm{BET}}\right)$ value obtained from the BET (Brunauer-Emmett-Teller) analysis reveals that the synthesized monoclinic tungsten oxide has values of $5.2 \mathrm{~m}^{2} \cdot \mathrm{g}^{-1}, 22.3 \mathrm{~nm}$ and $0.35 \mathrm{~cm}^{3} \cdot \mathrm{g}^{-1}$ respectively for surface area, pores diameter and pores volume.
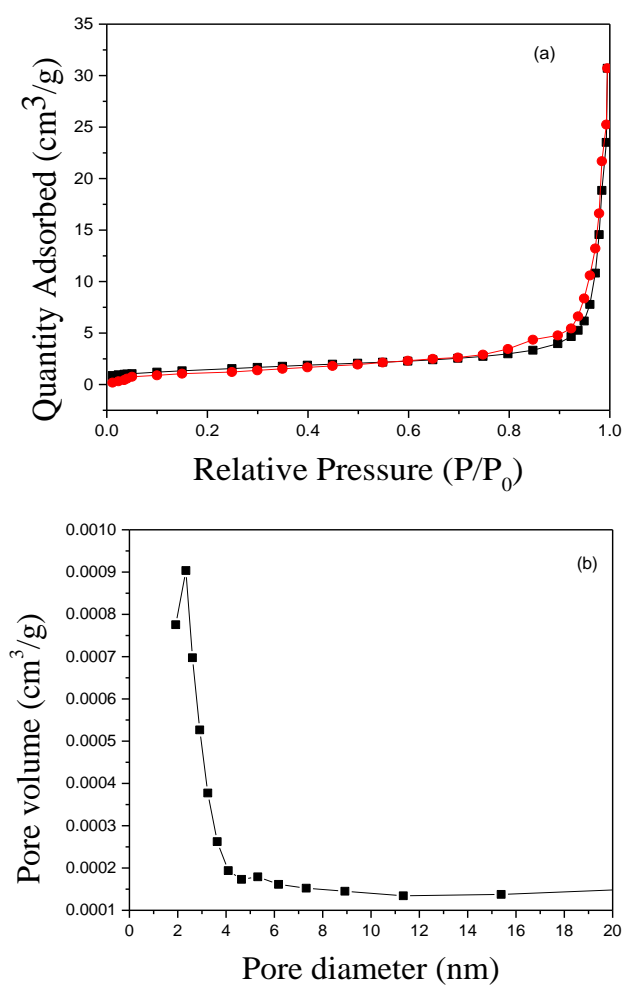

Fig. 6. $\mathrm{N}_{2}$ adsorption-desorption isotherms (a) and the pore size distribution curve (b) of $\mathrm{WO}_{3}$ 


\section{Catalytic activity of $\mathrm{WO}_{3}$ sample}

1. Catalytic efficiency of $\mathrm{WO}_{3}$ synthesized

To investigate the catalytic effect of synthesized $\mathrm{m}-\mathrm{WO}_{3}$ on the dye bleaching, the solutions were treated in the plasma reactor without catalyst (plasma alone), with catalyst added $\left(\right.$ plasma $\left.+\mathrm{m}-\mathrm{WO}_{3}\right)$ and use of catalyst like adsorbent $(\mathrm{m}-$ $\mathrm{WO}_{3}$ alone). The Fig. 7 shows the sunset yellow FCF beaching rate with $10.5,16.9$ and $52.5 \%$ for $\mathrm{m}-\mathrm{WO}_{3}$ alone, plasma alone and plasma $+\mathrm{m}-\mathrm{WO}_{3}$ respectively after $30 \mathrm{~min}$ of treatment. These results (Fig.7) show that the plasma treatment alone is not sufficient to obtain a high dye bleaching rate; the plasma treatment alone has given us a bleaching efficiency of $16.9 \%$ after $30 \mathrm{~min}$ treatment, this lower value of bleaching efficiency can be due to the quantity of oxidizing species generate by the gliding arc discharge inside the dye solution. Moreover, the bleaching efficiency obtained when the glidarc discharge is coupled with catalyst (plasma $+\mathrm{m}-\mathrm{WO}_{3}$ ) is highest than the total of plasma alone and catalyst alone. Nevertheless, the gliding discharge alone is able to fade the dye. The increasing of dye bleaching rate after the coupled treatment (plasma $+\mathrm{m}-\mathrm{WO}_{3}$ ) could be due to radiation from gliding arc discharge. Benstaali et al., [32] showed that the light generated by the gliding arc discharge is rich in ultraviolet radiations and the emergence of a photosensitive catalyst such as $\mathrm{WO}_{3}$. The $\mathrm{UV}$ radiations on $\mathrm{WO}_{3}$ might also enhance the formation of active ${ }^{\circ} \mathrm{OH}$ due to the ability of tungsten oxide to dissociate adsorbed water molecules. Equations 14-21 show the mechanism for degradation of dye using $\mathrm{WO}_{3}$ under radiation. In the mechanism, hole and electron pairs are generated by light irradiation.

$$
\begin{aligned}
& \mathrm{WO}_{3}+\mathrm{h} v \rightarrow \mathrm{h}^{+}+\mathrm{e}^{-} \\
& \mathrm{h}^{+}+\mathrm{H}_{2} \mathrm{O} \rightarrow \cdot \mathrm{OH}+\mathrm{H}^{+} \\
& \mathrm{h}^{+}+\mathrm{OH}^{-} \rightarrow \cdot \mathrm{OH} \\
& \mathrm{e}^{-}+\mathrm{O}_{2} \rightarrow \mathrm{O}_{2}^{-} \\
& \mathrm{O}_{2}^{-}+\mathrm{H}_{2} \mathrm{O} \rightarrow \mathrm{HO}_{2}^{\cdot}+\mathrm{OH}^{-} \\
& \mathrm{HO}_{2}{ }^{\cdot}+\mathrm{H}_{2} \mathrm{O} \rightarrow \mathrm{H}_{2} \mathrm{O}_{2}+{ }^{\cdot} \mathrm{OH} \\
& \mathrm{H}_{2} \mathrm{O}_{2}+\mathrm{h} v \rightarrow 2 \cdot{ }^{\cdot} \mathrm{OH} \\
& { }^{\circ} \mathrm{OH}+\mathrm{SY}-\mathrm{FCF} \rightarrow \text { oxidation products }
\end{aligned}
$$

where $\mathrm{h}^{+}$refers to a positive hole.

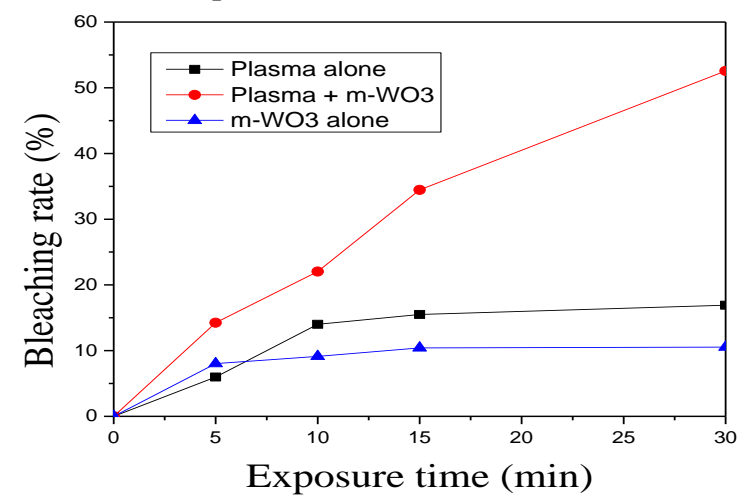

Fig.7. Bleaching efficiency of SY-FCF as a function of treatment time (substrate dye concentration: $25 \mathrm{mg} . \mathrm{L}^{-1}$, initial $\mathrm{pH}: 5$, catalyst concentration: 1 g.L.-
The HO radicals photo-generated added to HO radicals generated by gliding arc discharge thus accelerate the degradation process.

2. Effect of initial $\mathrm{pH}$ of the dye solution

The influence of $\mathrm{pH}$ on the bleaching efficiency of SYFCF $(25 \mathrm{mg} / \mathrm{L})$ was analyzed at a constant loading of catalyst $(1 \mathrm{~g} / \mathrm{L})$ by changing the initial $\mathrm{pH}$ of the aqueous solution (3 to 9). Fig.8 depicts that, the bleaching efficiency of SY-FCF decreases by raising the initial $\mathrm{pH}$. Indeed, the discoloration rate was decreased from 59.7 to $19.6 \%$ by increasing the initial $\mathrm{pH}$ from 3 to 9 . The bleaching rate decrease with the increase in reaction $\mathrm{pH}$ and high bleaching rate was obtained at $3.0 \mathrm{pH}$ as shown in Fig. 8, the greater bleaching efficiency at $\mathrm{pH} 3.0$ can be explained by the isoelectric point (pHIEP) of the catalyst which corresponds to the zeta potential equal to zero. At $\mathrm{pH}$ values greater than $\mathrm{pHIEP}(\mathrm{pH}>\mathrm{pHIEP})$, the catalyst surface becomes more negatively charged, the dye used in this study was anionic dye and was negatively charged under experimental conditions. The decreasing of the bleaching efficiency can also be explained by the direct competition between the $\mathrm{OH}^{\cdot}$ radicals produce on the surface of the catalyst (reaction of $\mathrm{h}^{+}$and adsorbed $\mathrm{OH}^{-}$) also some negatively charged species [9], [15], [16], [33]. Meanwhile, in acid medium ( $\mathrm{pH}<\mathrm{pHIEP}$ ) the catalyst surface becomes positively charged In such case, the electrostatic attraction between the positively charged surface and the anionic dye may result in an increased discoloration process [34].

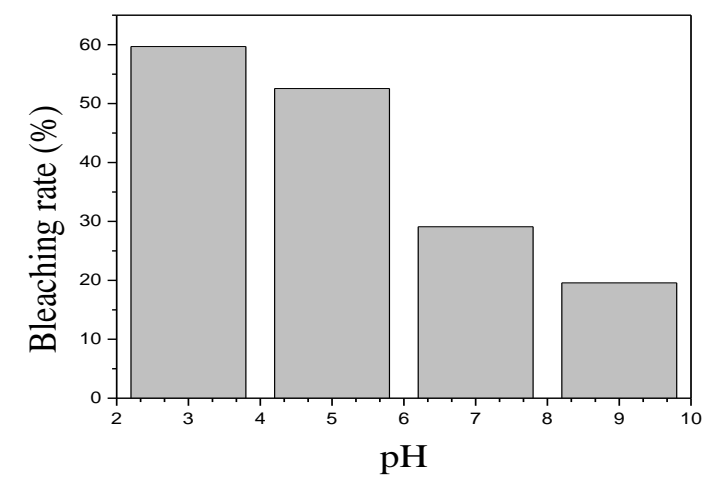

Fig. 8. Effect of initial $\mathrm{pH}$ of substrate dye solution on bleaching rate (dye concentration: $25 \mathrm{mg} . \mathrm{L}^{-1}$, catalyst concentration: 1 g.L $\mathrm{L}^{-1}$, time: $30 \mathrm{~min}$ ).

\section{Effect of catalyst concentration}

The effect of the catalyst concentration on bleaching process of SY-FCF $(25 \mathrm{mg} / \mathrm{L})$ was studied at $\mathrm{pH}$ 5. As shown in Fig. 9 the bleaching rate increase from 25.04 to $52.56 \%$ when the catalyst dosage increases from 0.5 to $1 \mathrm{~g} / \mathrm{L}$, however for the catalyst dosage above $1 \mathrm{~g} / \mathrm{L}$ the bleaching rate decreases. The bleaching efficiency up to $1 \mathrm{~g} / \mathrm{L}$ can be explained by the fact that more photocatalyst leads to the reaction of more reactive species. In many cases due to the increase of the active sites as well as by the generation of free electrons in the conduction band during photocatalysis process, the rate of photocatalytic bleaching of organics pollutants increases with photocatalyst loading [21], [23][25]. Indeed, at lower catalyst dosage, more light is transmitted through the reactor to increase of hydroxyl radical produced from the irradiated catalyst. However, beyond the optimum amount of catalyst dosage, the discoloration efficiency can be expected to decrease due to the increase of the density of aqueous solution and thus be increasing the 
light dispersion. Moreover, the agglomerations due to increasing of catalyst dosage reduce the number of surface adsorption sites and thus decrease the photocatalytic activity [35].

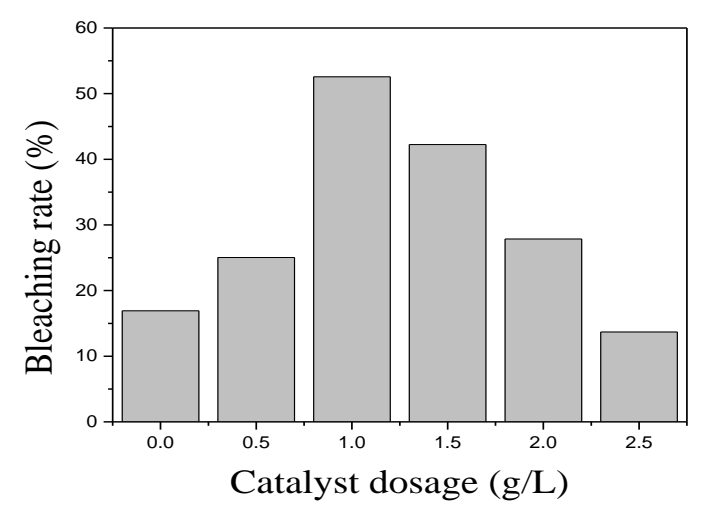

Fig. 9. The effect of photocatalyst dosage on the on bleaching rate of SYFCF (substrate dye concentration: $25 \mathrm{mg} . \mathrm{L}^{-1}$, initial pH: 5, time: $30 \mathrm{~min}$ ).

\section{CONCLUSION}

In this present work, the plasma-catalytic efficiency on the discoloration has been proven. The gliding arc discharge plays a double role during the bleaching process. The catalyst used in this work has been successfully synthesized via acid precipitation. The $\mathrm{WO}_{3}$ obtained was used as photocatalysts for the discoloration enhancement of SY-FCF solution in glidarc plasma reactor. The $\mathrm{pH}$ of the solution and the catalyst concentration has an important role in the bleaching process. These experiments allow us to conclude that the assynthesized catalyst presented efficiency in the discoloration of SY-FCF solutions and the plasma which is a rich medium of reactive species and sources of UV radiation could be used in the aim to improve the discoloration by coupling with $\mathrm{m}$ $\mathrm{WO}_{3}$ incorporated.

\section{ACKNOWLEDGMENT}

Authors are grateful to Dr Boyom Tatchemo Frank of the "Universite Catholique de Louvain" (Belgium) for the characterizations made in this work and thank Prof. Doubla Avaly $^{+}$for plasma reactor support.

\section{REFERENCES}

[1] F. M. D. Chequer, G. A. R. de Oliveira, E. R. A. Ferraz, J. C. Cardoso, M. V. B. Zanoni, and D. P. de Oliveira, 'Textile Dyes: Dyeing Process and Environmental Impact', Eco-Friendly Textile Dyeing and Finishing, Jan. 2013, doi: 10.5772/53659.

[2] K. Singh and S. Arora, 'Removal of Synthetic Textile Dyes From Wastewaters: A Critical Review on Present Treatment Technologies', Critical Reviews in Environmental Science and Technology, vol. 41, no. 9, pp. 807-878, Apr. 2011, doi: 10.1080/10643380903218376.

[3] G. R. Bamwenda and H. Arakawa, 'The visible light induced photocatalytic activity of tungsten trioxide powders', Applied Catalysis A: General, vol. 210, no. 1, pp. 181-191, Mar. 2001, doi: 10.1016/S0926-860X(00)00796-1.

[4] X. F. Cheng, W. H. Leng, D. P. Liu, J. Q. Zhang, and C. N. Cao, 'Enhanced photoelectrocatalytic performance of Zn-doped WO3 photocatalysts for nitrite ions degradation under visible light', Chemosphere, vol. 68, no. 10, pp. 1976-1984, Aug. 2007, doi: 10.1016/j.chemosphere.2007.02.010.

[5] S. J. Hong, H. Jun, P. H. Borse, and J. S. Lee, 'Size effects of WO3 nanocrystals for photooxidation of water in particulate suspension and photoelectrochemical film systems', International Journal of Hydrogen Energy, vol. 34, no. 8, pp. 3234-3242, May 2009, doi: 10.1016/j.ijhydene.2009.02.006.

[6] D. B. Hernandez-Uresti, D. Sánchez-Martínez, A. Martínez-de la Cruz, S. Sepúlveda-Guzmán, and L. M. Torres-Martínez, 'Characterization and photocatalytic properties of hexagonal and monoclinic WO3 prepared via microwave-assisted hydrothermal synthesis', Ceramics International, vol. 40, no. 3, pp. 4767-4775, Apr. 2014, doi: 10.1016/j.ceramint.2013.09.022.

[7] I. Turyan, U. O. Krasovec, B. Orel, T. Saraidorov, R. Reisfeld, and D Mandler, "Writing-Reading-Erasing" on Tungsten Oxide Films Using the Scanning Electrochemical Microscope', Advanced Materials, vol. 12, no. 5, pp. 330-333, 2000, doi: https://doi.org/10.1002/(SICI)1521-4095(200003)12:5<330::AIDADMA330>3.0.CO;2-8.

[8] N. Aqilah Mohd Razali et al., 'Palm oil mill effluent treatment using tungsten trioxide: Adsorption and photocatalytic degradation', Materials Today: Proceedings, Sep. 2020, doi: 10.1016/j.matpr.2020.08.424.

[9] F. Amano, E. Ishinaga, and A. Yamakata, 'Effect of Particle Size on the Photocatalytic Activity of WO3 Particles for Water Oxidation', $J$. Phys. Chem. C, vol. 117, no. 44, pp. 22584-22590, Nov. 2013, doi: $10.1021 / \mathrm{jp} 408446 \mathrm{u}$.

[10] K. A. Newton and F. E. Osterloh, 'Size and Morphology of Suspended WO3 Particles Control Photochemical Charge Carrier Extraction and Photocatalytic Water Oxidation Activity', Top Catal, vol. 59, no. 8, pp. 750-756, May 2016, doi: 10.1007/s11244-016-0549-3.

[11] C. Santato, M. Odziemkowski, M. Ulmann, and J. Augustynski, 'Crystallographically Oriented Mesoporous WO 3 Films: Synthesis, Characterization, and Applications', J. Am. Chem. Soc., vol. 123, no. 43, pp. 10639-10649, Oct. 2001, doi: 10.1021/ja011315x.

[12] J. Shieh, H. M. Feng, M. H. Hon, and H. Y. Juang, 'WO3 and $\mathrm{W} \square \mathrm{Ti} \square \mathrm{O}$ thin-film gas sensors prepared by sol-gel dip-coating', Sensors and Actuators B: Chemical, vol. 86, no. 1, pp. 75-80, Aug. 2002, doi: 10.1016/S0925-4005(02)00150-8.

[13] Y.-G. Choi, G. Sakai, K. Shimanoe, N. Miura, and N. Yamazoe, 'Preparation of aqueous sols of tungsten oxide dihydrate from sodium tungstate by an ion-exchange method', Sensors and Actuators B: Chemical, vol. 87, no. 1, pp. 63-72, Nov. 2002, doi: 10.1016/S09254005(02)00218-6.

[14] D. Sánchez-Martínez, C. Gomez-Solis, and L. M. Torres-Martinez, 'CTAB-assisted ultrasonic synthesis, characterization and photocatalytic properties of WO3', Materials Research Bulletin, vol. 61, pp. 165-172, Jan. 2015, doi: 10.1016/j.materresbull.2014.10.034.

[15] M. Verma, K. P. Singh, and A. Kumar, 'Reactive magnetron sputtering based synthesis of WO3 nanoparticles and their use for the photocatalytic degradation of dyes', Solid State Sciences, vol. 99, p. 105847, Jan. 2020, doi: 10.1016/j.solidstatesciences.2019.02.008.

[16] G. Jeevitha, R. Abhinayaa, D. Mangalaraj, and N. Ponpandian, 'Tungsten oxide-graphene oxide (WO3-GO) nanocomposite as an efficient photocatalyst, antibacterial and anticancer agent', Journal of Physics and Chemistry of Solids, vol. 116, pp. 137-147, May 2018, doi: 10.1016/j.jpcs.2018.01.021.

[17] B. Behera and S. Chandra, 'Synthesis of WO3 nanorods by thermal oxidation technique for NO2 gas sensing application', Materials Science in Semiconductor Processing, vol. 86, pp. 79-84, Nov. 2018, doi: 10.1016/j.mssp.2018.06.022.

[18] N. Bashirom and Q. L. Lee, 'Synthesis of Visible-Light Active Monoclinic $\mathrm{WO}_{3}$ by Thermal Oxidation of Tungsten Powder for Photoreduction of Cr(VI)', MSF, vol. 1010, pp. 405-410, Sep. 2020, doi: 10.4028/www.scientific.net/MSF.1010.405.

[19] M. Laroussi and F. Leipold, 'Evaluation of the roles of reactive species, heat, and UV radiation in the inactivation of bacterial cells by air plasmas at atmospheric pressure', International Journal of Mass Spectrometry, vol. 233, no. 1, pp. 81-86, Apr. 2004, doi: 10.1016/j.ijms.2003.11.016.

[20] J.-L. Brisset et al., 'Chemical Reactivity of Discharges and Temporal Post-Discharges in Plasma Treatment of Aqueous Media: Examples of Gliding Discharge Treated Solutions', Ind. Eng. Chem. Res., vol. 47, no. 16, pp. 5761-5781, Aug. 2008, doi: 10.1021/ie701759y.

[21] A. P. Mbouopda et al., 'New-route synthesis of N-doped $\mathrm{TiO} 2$ via exposing the $\mathrm{TiCl} 3$ precursor to non-thermal quenched plasma at various times', Materials Chemistry and Physics, vol. 206, pp. 224231, Feb. 2018, doi: 10.1016/j.matchemphys.2017.12.019.

[22] F. W. Boyom-Tatchemo, F. Devred, G. Ndiffo-Yemeli, S. Laminsi, and E. M. Gaigneaux, 'Plasma-induced redox reactions synthesis of nanosized $\alpha-, \gamma$ - and $\delta$-MnO2 catalysts for dye degradation', Applied Catalysis B: Environmental, vol. 260, p. 118159, Jan. 2020, doi: 10.1016/j.apcatb.2019.118159. 
[23] F. W. B. Tatchemo et al., 'Gliding Arc Plasma Synthesis of $\mathrm{MnO} 2$ Nanorods for the Plasma-Catalytic Bleaching of Azoïc Amaranth Red Dye', Top Catal, vol. 60, no. 12, pp. 962-972, Aug. 2017, doi: 10.1007/s11244-017-0761-9.

[24] A. Tiya-Djowe, E. Acayanka, G. Lontio-Nkouongfo, S. Laminsi, and E. M. Gaigneaux, 'Enhanced discolouration of methyl violet 10B in a gliding arc plasma reactor by the maghemite nanoparticles used as heterogeneous catalyst', Journal of Environmental Chemical Engineering, vol. 3, no. 2, pp. 953-960, Jun. 2015, doi: 10.1016/j.jece.2014.11.016.

[25] S. A. Djepang, S. Laminsi, E. Njoyim-Tamungang, C. Ngnintedem, and J.-L. Brisset, 'Plasma-Chemical and Photo-Catalytic Degradation of Bromophenol Blue', Chemical and Materials Engineering, vol. 2, no. 1, pp. 14-23, Jan. 2014, doi: 10.13189/cme.2014.020103.

[26] D. Moussa, F. Abdelmalek, B. Benstaali, A. Addou, E. Hnatiuc, and J.L. Brisset, 'Acidity control of the gliding arc treatments of aqueous solutions: application to pollutant abatement and biodecontamination', Eur. Phys. J. Appl. Phys., vol. 29, no. 2, Art. no. 2, Feb. 2005, doi: 10.1051/epjap:2004211.

[27] J. Deng et al., 'Magnetic and conducting Fe3O4-cross-linked polyaniline nanoparticles with core-shell structure', Polymer, vol. 43, no. 8, pp. 2179-2184, Apr. 2002, doi: 10.1016/S0032-3861(02)000460 .

[28] M. H. Sayed Abhudhahir and J. Kandasamy, 'Photocatalytic effect of manganese doped WO3 and the effect of dopants on degradation of methylene blue', J Mater Sci: Mater Electron, vol. 26, no. 11, pp. 8307-8314, Nov. 2015, doi: 10.1007/s10854-015-3496-z.

[29] M. F. Daniel, B. Desbat, J. C. Lassegues, B. Gerand, and M. Figlarz, 'Infrared and Raman study of WO3 tungsten trioxides and WO3, xH2O tungsten trioxide tydrates', Journal of Solid State Chemistry, vol. 67 no. 2, pp. 235-247, Apr. 1987, doi: 10.1016/0022-4596(87)90359-8.

[30] U. Opara Krašovec, A. Šurca Vuk, and B. Orel, 'IR Spectroscopic studies of charged-discharged crystalline WO3 films', Electrochimica Acta, vol. 46, no. 13, pp. 1921-1929, Apr. 2001, doi: 10.1016/S00134686(01)00361-9.

[31] O. Rezaee, H. Mahmoudi Chenari, and F. E. Ghodsi, 'Precipitation synthesis of tungsten oxide nanoparticles: X-ray line broadening analysis and photocatalytic efficiency study', J Sol-Gel Sci Technol, vol. 80, no. 1, pp. 109-118, Oct. 2016, doi: 10.1007/s10971-016-40735 .

[32] B. Benstaali, P. Boubert, B. G. Cheron, A. Addou, and J. L. Brisset, 'Density and Rotational Temperature Measurements of the $\mathrm{OH}^{\circ}$ and $\mathrm{NO}^{\circ}$ Radicals Produced by a Gliding Arc in Humid Air', Plasma Chemistry and Plasma Processing, vol. 22, no. 4, pp. 553-571, Dec. 2002, doi: 10.1023/A:1021371529955.

[33] M. Qamar, M. A. Gondal, K. Hayat, Z. H. Yamani, and K. AlHooshani, 'Laser-induced removal of a dye C.I. Acid Red 87 using ntype WO3 semiconductor catalyst', Journal of Hazardous Materials, vol. 170, no. 2, pp. 584-589, Oct. 2009, doi: 10.1016/j.jhazmat.2009.05.099.

[34] K. Hayat, M. A. Gondal, M. M. Khaled, Z. H. Yamani, and S. Ahmed, 'Laser induced photocatalytic degradation of hazardous dye (SafraninO) using self synthesized nanocrystalline WO3', Journal of Hazardous Materials, vol. 186, no. 2, pp. 1226-1233, Feb. 2011, doi: 10.1016/j.jhazmat.2010.11.133.

[35] A. Gnanaprakasam, V. M. Sivakumar, and M. Thirumarimurugan, 'Influencing Parameters in the Photocatalytic Degradation of Organic Effluent via Nanometal Oxide Catalyst: A Review', Indian Journal of Materials Science, vol. 2015, pp. 1-16, Sep. 2015, doi: $10.1155 / 2015 / 601827$. 